\title{
Transformation of Mouse Macrophages by Simian Virus 40
}

\author{
LAWRENCE B. STONE AND KENNETH K. TAKEMOTO
}

Laboratory of Viral Diseases, National Institute of Allergy and Infectious Diseases, Bethesda, Maryland 20014

\author{
Received for publication 13 July 1970
}

\begin{abstract}
Studies were undertaken to prove that simian virus 40 (SV40) can transform the mouse macrophage, a cell type naturally restricted from deoxyribonucleic acid (DNA) replication. Balb/C macrophages infected with SV40 demonstrated T-antigen production and induced DNA synthesis simultaneously. In the absence of apparent division, these cells remained $T$ antigen-positive for at least 45 days. SV40 could be rescued from nondividing, unaltered macrophages during the $T$ antigen-producing period. Proliferating transformants appeared at an average of 66 days post-SV40 infection. Established cell lines were T antigen-positive and were negative for infectious virus, but yielded SV40 after fusion with African green monkey kidney cells. Their identity as transformed macrophages was substantiated by evaluation of cellular morphology, phagocytosis, acid phosphatase, $\beta_{1 \mathrm{c}}$ synthesis, and aminoacridine incorporation.
\end{abstract}

Transformation by oncogenic deoxyribonucleic acid (DNA) viruses in vitro has been primarily studied in cell types which have an unlimited capacity for growth. Morphologically, these cells are either fibroblastic or epitheloid and generally do not possess differentiated functions. In this case, a new protein known as tumor $(T)$ antigen appears in the cell nucleus shortly after infection (3). Then, after 10 to 14 days, a fraction of this infected population emerges as recognizable phenotypic transformants. It is not known whether oncogenic viruses can effect these same events in differentiated cells which, despite the capacity for division, remain arrested in the postmitotic state. The peritoneal macrophage, naturally representative of this restriction, would be a useful model for evaluation of this possibility. Derived from progenitors which have undergone mitosis, it maintains ribonucleic acid (RNA) and protein synthesis $(9,18,25)$ without entering the $S$ period of DNA replication $(4,25)$. After polyoma infection, mouse peritoneal macrophages have been previously noted to undergo DNA and T-antigen synthesis (14). The myocyte another differentiated nondividing cell type, has also been reported to undergo DNA and T-antigen synthesis after either simian virus 40 (SV40) or polyoma infection (6).

Observations in our laboratory have indicated significant and persistent $\mathrm{T}$-antigen production in the macrophage after exposure to SV40. This paper further documents the capacity of SV40 to induce morphological transformation of the $G_{1}$ arrested mouse peritoneal macrophage. Simultaneous preliminary reports of these findings (Bacteriol. Proc., p. 188, 1970), and the similar observations of Mauel and Defendi (Bacteriol. Proc., p. 180, 1970) have been recently made.

\section{MATERIALS AND METHODS}

Tissue culture. Peritoneal macrophages were harvested from 6-week male $\mathrm{Balb} / \mathrm{c}$ mice as described elsewhere (22), but without previous stimulation to insure homogeneity and function, and to prevent the induction of nonspecific DNA synthesis $(7,24)$. These cells were plated at a density of $2.5 \times 10^{5}$ in Eagle's medium containing $10 \%$ fetal bovine serum and antibiotics onto 60-mm plastic petri dishes (Falcon Plastics). Cultures for fluorescent-antibody (FA) and characterization studies were seeded at the same density onto glass cover slips $(10$ by $20 \mathrm{~mm}$ ). One hour after plating, the medium was changed to remove unattached cells. At 48 and $72 \mathrm{hr}$, the cultures were treated with $1 \mathrm{ml}$ of $0.25 \%$ trypsin. Since normal macrophages resist the effects of trypsin at this concentration, this procedure aided removal of other cell types. Phase microscopic examination of these cultures after 7 days of incubation at $37 \mathrm{C}$ in an atmosphere of $5 \% \mathrm{CO}_{2}$ and air revealed the distinct morphology of normal macrophages. Those cultures which were noted to have contaminating or questionable cell types were omitted from further experiments.

Virus Strains. The small-plaque mutant of SV40 (SV-S) rescued from transformed cells by co-cultivation with African green monkey kidney cells (AGMK; 20) was used in all experiments. Virus titer when assayed in primary AGMK was $5 \times 10^{7}$ plaque-forming units (PFU)/ml. Macrophage cultures were infected at a multiplicity of 100 . After adsorption for $1 \mathrm{hr}$, the 
cultures were washed with phosphate-buffered saline, pH 7.2 (PBS), and fresh medium was added. Controls were mock-infected at the same time.

Ultraviolet-inactivated Sendai virus [UV-SeV, 4,000 hemagglutinating (HA) units/ml] was prepared and used in fusion experiments as previously described (20).

FA technique. At intervals after SV40 infection, cover slips were harvested, washed twice in PBS, and fixed in acetone for $5 \mathrm{~min}$. They were immediately tested for SV40 T and viral (V) antigens by the indirect procedure. Anti-T and anti-V sera were produced in hamsters by the ascites method (19). Fluorescein isothiocyanate-conjugated goat, anti-hamster globulin was obtained from the National Cancer Institute. Lissamine rhodamine bovine serum albumin was employed as a counterstain.

DNA synthesis. At times correspondent to those chosen for FA tests, macrophage cultures were pulselabeled for $60 \mathrm{~min}$ with $100 \mu \mathrm{Ci}$ of ${ }^{3} \mathrm{H}-5$-methyl-thymidine $\left({ }^{3} \mathrm{H}\right.$-TdR, $\mathrm{A}_{0}=20 \mathrm{Ci} / \mathrm{mmole} ; \mathrm{New}$ England Nuclear Corp.). Cells were lysed with $0.4 \%$ sodium dodecyl sulfate (SDS) in the presence of $0.1 \mathrm{M} \mathrm{NaCl}$ at $p \mathrm{H}$ 8.0. Trichloroacetic acid-precipitable DNA from the lysate was absorbed on cellulose nitrate filters (Schleicher and Schuell * B6). These filters were dried and placed in vials, and the radioactivity was determined by liquid scintillation spectrometry.

Macrophage characterization. Macrophages were evaluated for phagocytic activity by use of a sterile colloidal suspension of carbon particles. After exposure to this material for $24 \mathrm{hr}$, the culture medium was changed and cells were observed for the presence of cytoplasmic carbon by phase microscopy. They were considered active phagocytes only if ingested material was maintained after successive passage.

The Gomori technique (10) was employed to demonstrate acid phosphatase with the use of a $\beta$ glycerol phosphate substrate and $\left(\mathrm{NH}_{4}\right)_{2} \mathrm{~S}$ to precipitate $\mathrm{PbS}$ at the sites of enzyme activity. Cells were exposed to cold $2.5 \%$ glutaraldehyde for $10 \mathrm{~min}$ prior to staining to damage lysosomal membranes and make them accessible to the substrate. Incubation was limited to $20 \mathrm{~min}$ to improve definition of precipitated cytoplasmic granules. Analysis of concentrated culture fluids for beta-1-C globulin $\left(\beta_{1 \mathrm{c}}, \mathrm{C}^{\prime} 3\right)$, an immunoprotein elaborated by murine macrophages, was performed as described elsewhere (18).

\section{RESULTS}

At $8 \mathrm{hr}$ after SV40 infection, all macrophages became round and more refractile in appearance. Their general morphology was similar to that of monocytic cell types. After another $24 \mathrm{hr}$, pseudopodia and peripheral spikes (15) were again visible. SV40 $T$ antigen was first seen by FA staining at $24 \mathrm{hr}$ in less than $1 \%$ of the cells. By $144 \mathrm{hr}, 100 \%$ of the cells were $\mathrm{T}$ antigen-positive. Periodic examination of cover slips up to 45 days after infection revealed persistent $T$-antigen fluorescence of unchanging intensity in all of the cells. V antigen was never detected.
Induced DNA synthesis was first observed 48 hr after virus infection. Trichloroacetic acidprecipitable activity increased to a maximum of 6,000 counts/min by $72 \mathrm{hr}$ and decayed to control values by $144 \mathrm{hr}$. Thymidine incorporation into mock-infected control cultures did not rise above background levels. No mitotic figures were evident in replicate cultures during this interval. A plot of these data correlated with the kinetics of T-antigen synthesis is presented in Fig. 1.

After these events, the infected cells entered a period of quiescence during which neither proliferation nor changes in morphology or function were apparent. During this interval, which averaged 54 days in length, trypsinization failed to yield any trypsin-sensitive cell population. All uninfected macrophages had degenerated by this time. Between 60 and 72 days after infection, foci of rapidly dividing cells appeared (Fig. $2 \mathrm{a}$ and $2 \mathrm{~b}$ ). Unlike normal macrophages, these cells could be removed with trypsin. Unlike other SV40 transformants, considerable pleomorphism was evident. Eight clonal lines were established and all were positive for $T$ antigen (Fig. 3A). These

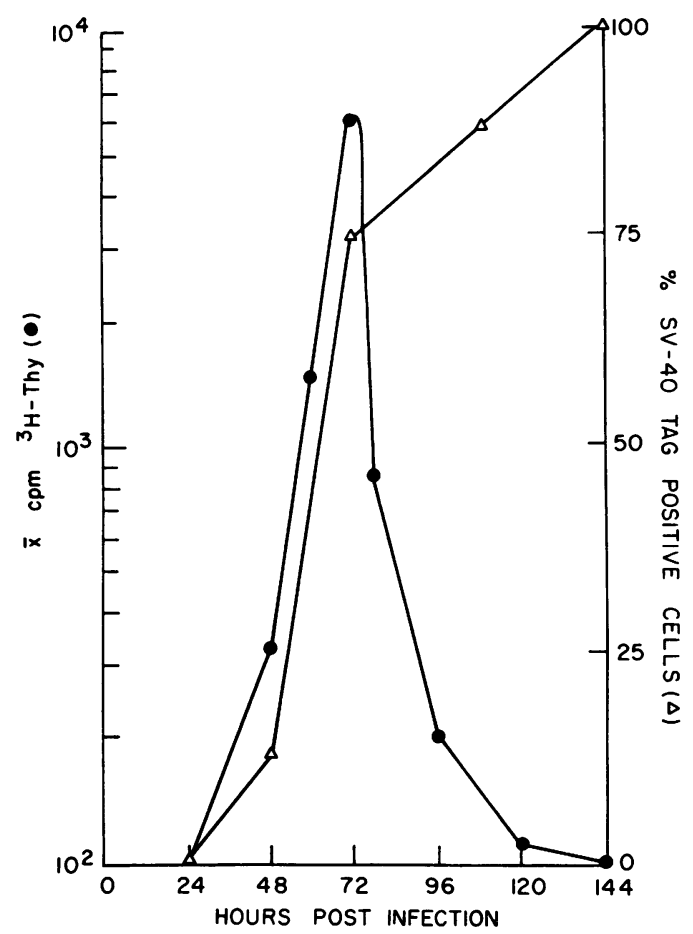

FIG. 1. Rate of induced DNA synthesis (O) after $S V 40$ infection (multiplicity of infection, 100) of Balb/C macrophages (as measured by ${ }^{3} H-T d R$ uptake into trichloroacetic acid-precipitable DNA in a 1-hr labeling period) compared to percentage of $T$-antigen-positive cells $(\triangle)$ by indirect $F A$. 


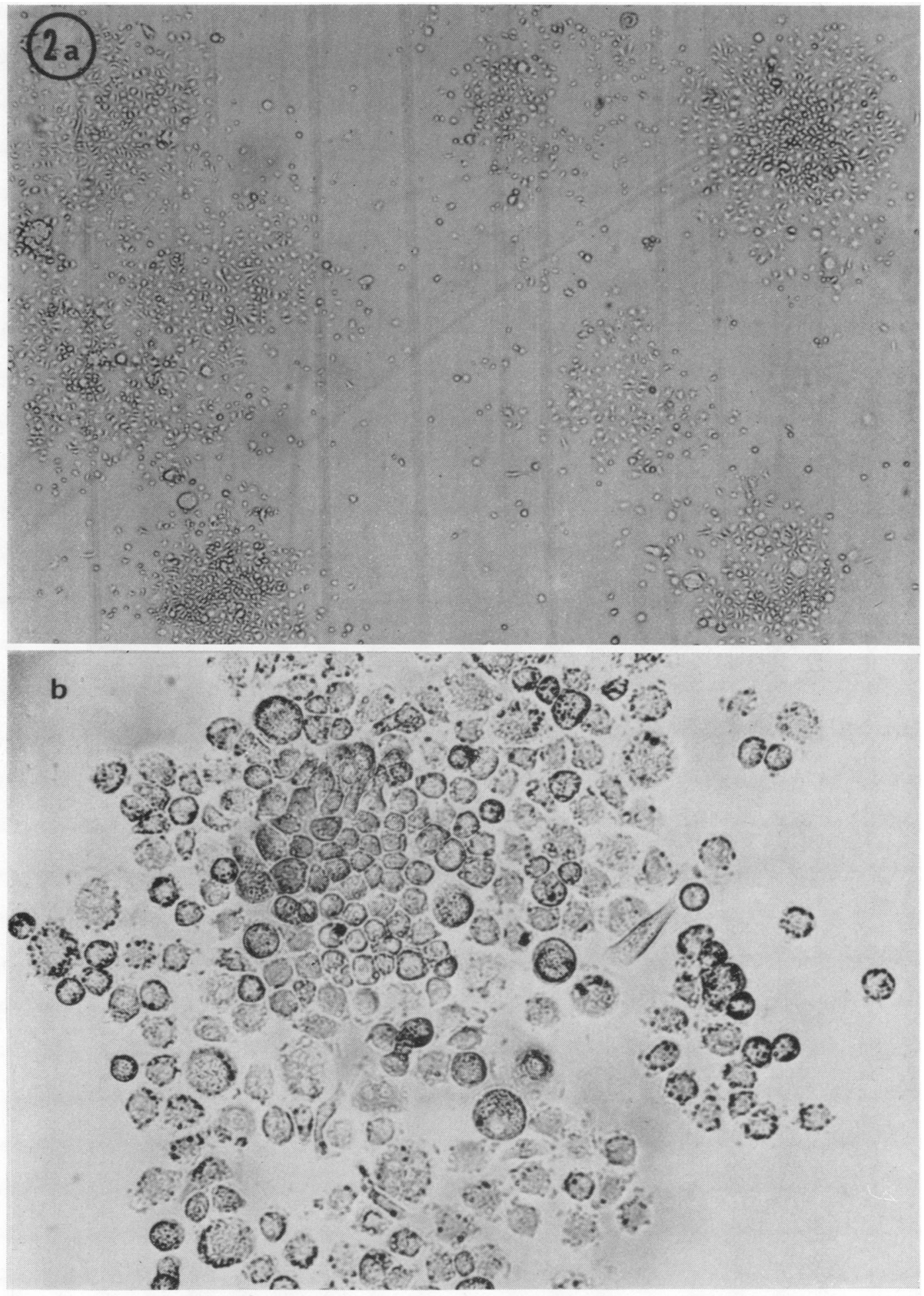

FIG. 2. (a) Emerging colonies of dividing transformed macrophages 60 days after SV40 infection $(\times 25)$. (b) Higher magnification of transformants from Fig. 2a. Pleomorphism is evident $(\times 160)$. 

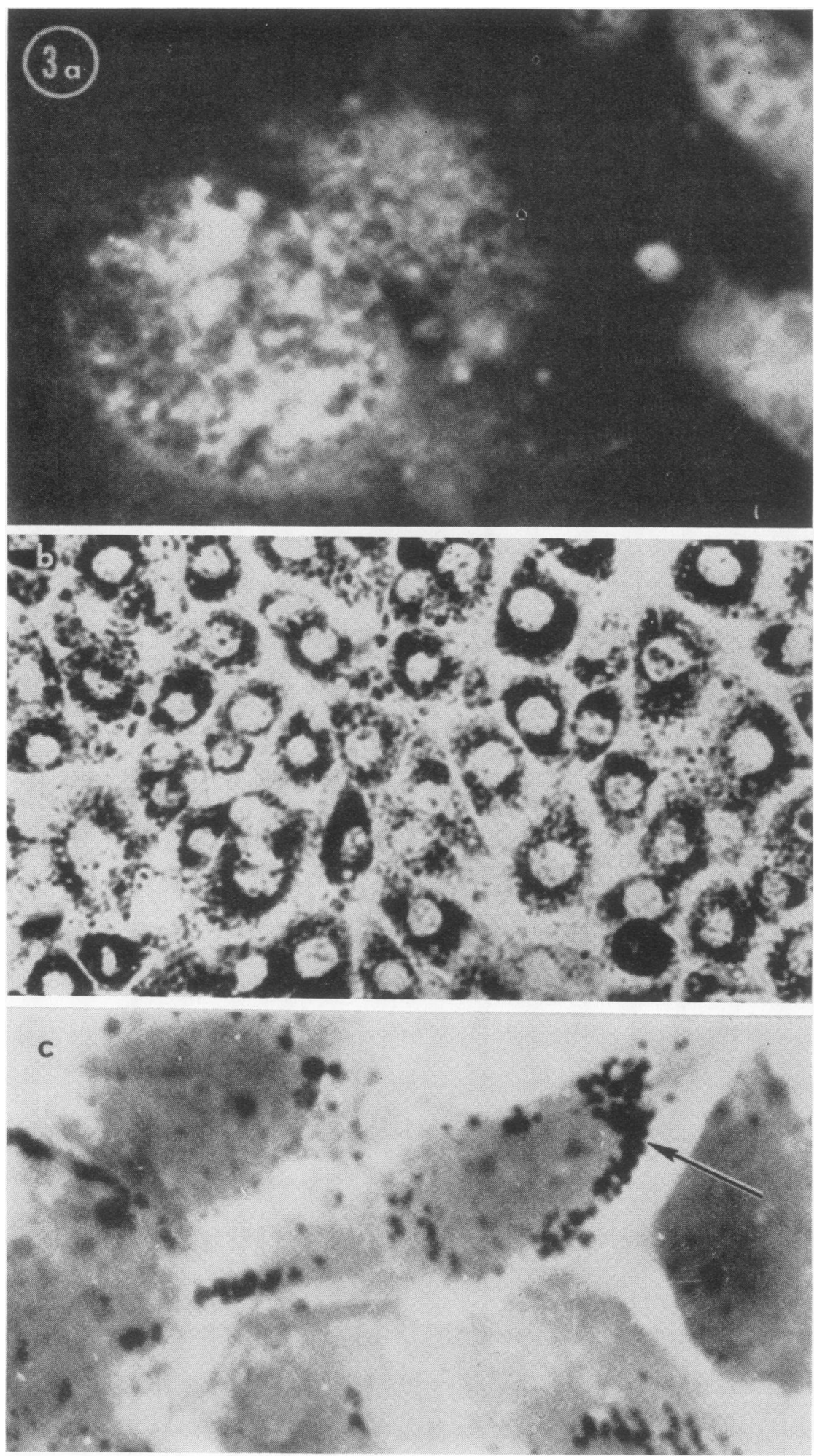

FIG. 3. (a) Intranuclear T antigen in clone 7, SV40-transformed macrophages $(\times 600)$. (b) Phagocytosis of suspended carbon (1/100) by clone 7 after 24 hr of incubation $(\times 225)$. (c) Acid phosphatase as demonstrated by the Gomori technique. Arrow indicates deposits of perinuclear PbS at lysosomal sites of enzyme $(\times 600)$. 
clonal lines have undergone 21 passages during 6 months in culture and are considered permanently established.

Rescue of SV40 from T antigen-producing, nondividing macrophages. Abortively infected mouse cells which do not become transformed fail to produce detectable $\mathrm{T}$ antigen after two or three generations (16). Since SV40-infected macrophages were intensely $T$ antigen-positive for at least 45 days without evident morphological alteration, attempts were made to rescue SV40 from these cells. SV-T antigen-producing (SV$\mathrm{T}+$ ) macrophages were maintained in SV40 antiserum for 20 days beginning 3 days after infection. As these cells could not be trypsinized, the fusion procedure was modified in the following manner. Uv-SeV (4,000 HA units) was directly added to the cultures and maintained at $4 \mathrm{C}$ for $15 \mathrm{~min}$. Permissive cells (AGMK) in a ratio of $10: 1$ were then added to this mixture. These cultures were kept at $4 \mathrm{C}$ for another 15 min and thereafter were incubated at $37 \mathrm{C}$. The medium was changed after the monkey kidney cells had settled (30 to $60 \mathrm{~min}$ ), thus removing the excess UV-SeV inoculum. After $24 \mathrm{hr}$, the plates were washed three times in PBS, and fresh medium was again added. After 20 days, these cultures were frozen and thawed twice, and the clarified supernatant fluids were assayed for SV40 in primary AGMK cells. Subsequently, $3.5 \times 10^{3}$ PFU of virus per $\mathrm{ml}$ was recovered. Other $\mathrm{T}$ antigen-producing macrophages, similarly maintained in antiserum and disrupted by freeze-thawing, were tested for residual SV40 by inoculation of primary AGMK cells. No virus was detected after 26 days of culture followed by a second passage in fresh AGMK cells. Controls of normal macrophages, uninfected AGMK, and UV-SeV-infected AGMK were all negative for SV40.

Recovery of infectious virus from morphologically transformed macrophages. SV40 was rescued from three of the clonal lines by the fusion technique. The average titer of virus recovered was $10^{5} \mathrm{PFU} / \mathrm{ml}$. Infectious virus was not isolated from freeze-thawed preparations of transformed macrophage cultures.

Characterization of transformants. Evaluation of the SV40 transformants was based upon the known properties of normal macrophages.

Phagocytosis. Uptake of colloidal carbon from medium was noted in the transformants and was equivalent to the activity of normal macrophages (Fig. 3b). Medium clearance required approximately $24 \mathrm{hr}$ for both cell types. Carbon ingested by the cells remained in the cytoplasm despite medium changes and was segregated into distinct vacuoles. Loss of this material occurred only after numerous cell divisions. Control cultures of secondary mouse embryo fibroblasts ( $\left.2^{\circ} \mathrm{MEF}\right)$ were not active phagocytes.

Acid phosphatase. Gomori staining revealed highly positive cells after a 20-min incubation with substrate (Fig. 3c). Large storage granules were distributed throughout the cytoplasm of the transformants. Few areas of incorporation were present in control cells (SV-Balb/C 3T3 and $2^{\circ}$ Balb/C fibroblasts), none of which approached the staining levels observed in both normal and transformed macrophages. Vital incorporation of dilute euchrysene $(1: 1,000,000)$, an aminoacridine which binds to lysosomal membranes (17; the site of acid phosphatase) confirmed this relationship among these same cell types.

Complement. A substantial arc of $\beta_{1 \mathrm{c}}$ was observed in the immunoelectrophoretic pattern of medium derived from transformants. Normal macrophages elaborated equal amounts of this protein whereas control medium did not produce a $\beta_{\text {1c }}$ pattern.

Attempts to induce tumors. Newborn syngeneic animals, both thymectomized and not thymectomized, were inoculated subcutaneously with up to $10^{7}$ transformed macrophages. No tumors have developed during more than 4 months of observation.

\section{DISCUSSION}

Endocytosis, a trait commonly used to identify the macrophage, is observed to a limited extent in other cell types (1). Thus, the singular use of this property for identification may be misleading. A more accurate characterization can be made by consideration of multiple cellular functions. In this strict sense, many similarities between normal and SV40-transformed macrophages are apparent. The association of phagocytes with welldeveloped lysosomal enzymes (presumably for digestive processes) has been recognized (4). The high activity of these markers more specifically defines a cell possessing true endocytic function. Furthermore, secondary criteria, including aminoacridine incorporation, $\beta_{1 \mathrm{c}}$ synthesis, and morphological considerations, define the SV40 transformant as a closely related counterpart of the normal macrophage. The data reported here clearly indicate that SV40 is capable of inducing transformation in this naturally nondividing and differentiated cell type.

Differing from the murine fibroblast, which undergoes SV40 conversion in approximately 14 days (21), the macrophage required an average of 66 days to express morphological transformation. In addition, during the preconversion interval, the SV40-infected macrophage continued to 
produce $T$ antigen, yet remained in the nondividing, phenotypically unaltered state. The fact that infectious SV40 could be recovered during this period would indicate that such cells harbor viral information without manifesting morphological transformation.

In two experiments, transformants emerged only from mature cells which approached the estimated 60-day life span of the normal macrophage $(5,12)$. The presence of viral genome alone was obviously not sufficient to initiate conversion. In the macrophage, those mechanisms which maintain the differentiated $G_{1}$ state may be responsible for repressing phenotypic transformants. Age-associated decay of these controls possibly contributed to the eventual appearance of SV40-altered cells. Infection of previously "aged" macrophages should then be expected to yield transformants at an earlier time.

The significance of induced cellular DNA synthesis $(8,11,14)$ by SV40 or polyoma and the function of $T$ antigen in productive or abortive infections by these viruses is not understood at the present time. The finding that both DNA replication and $\mathrm{T}$-antigen production occur synchronously in the Balb/C macrophage may be fortuitous. Nevertheless, the results of Vogt et al. (23) and Basilico et al. (2) indicate that, in the case of polyoma, the virus is directly involved in the induction of DNA replication since it occurs in the same cells which are synthesizing virus. Similar observations have been made with SV40 (13).

Todaro and Green have reported that "fixation" of transformation requires one cell generation since they did not observe SV40 conversion of nondividing, contact-inhibited mouse 3T3 cells (21). They also indicated that virus-induced DNA synthesis did not occur under these circumstances (21). However, Henry et al. (11) demonstrated host DNA replication in the same system after a high multiplicity of SV40. We have noted that transformation does occur in these contactinhibited mouse embryo fibroblasts under similar conditions of infection (unpublished data). The SV40-macrophage interaction conclusively proves that transformation can be induced by this agent irrespective of the host cell's preinfection interphase state. Furthermore, this implies that the period of virus-induced DNA synthesis represents initial events which result in eventual transformation. Disregarding modifying host factors, one may postulate that transformation can potentially occur in any cell type as long as DNA replication is induced by the infecting oncogenic virus. Although not proven, it is possible that induced DNA synthesis reflects the period of viral genome integration. Further studies are necessary to establish this hypothesis.

\section{ACKNOWLEDGMENT}

We thank Richard Asofsky for kindly performing the immunoprotein analysis.

\section{LITERATURE GITED}

1. Amano, T., K. Takahashi, E. Okamoto, and O. Minorikawa. 1969. Establishment of a macrophage cell line derived from a testicular interstitial cell tumor in $\mathbf{A} / \mathbf{J a x}$ strain mice. Lab. Invest. 20:170-177.

2. Basilico, C., G. Maren, and G. DiMayorca. 1966. Requirement for the integrity of the viral genome for the induction of host DNA synthesis by polyoma virus. Proc. Nat. Acad. Sci. U.S.A. 56:208-215.

3. Black, P., W. Rowe, H. Turner, and R. Huebner. 1963. A specific complement-fixing antigen present in SV40 tumor and transformed cells. Proc. Nat. Acad. Sci. U.S.A. 50: 1148-1156.

4. Cohn, Z. A. 1968. The structure and function of monocytes and macrophages. Advan. Immunol. 9:163-214.

5. Ebert, R. H., and H. W. Florey. 1939. The extravascular development of the monocyte observed in vivo. Brit. J. Exp. Pathol. 20:342-356.

6. Fogel, M., and V. Defendi. 1967. Infection of muscle cultures from various species with oncogenic DNA viruses (SV40 and polyoma). Proc. Nat. Acad. Sci. U.S.A. 58:967-973.

7. Forbes, I. J. 1966. Mitosis in mouse peritoneal macrophages. J. Immunol. 96:734-741.

8. Gershon, D., L. Sachs, and E. Winocour. 1966. The induction of cellular DNA synthesis by SV40 in contact inhibited and in X-irradiated cells. Proc. Nat. Acad. Sci. U.S.A. 56:918-925.

9. Glasgow, L. A., and K. Habel. 1963. Interferon production by mouse leukocytes in vitro and in vivo. J. Exp. Med. 117:149-163.

10. Gomori, G. 1952. Microscopic histochemistry: principles and practice, p. 193. Univ. of Chicago Press, Chicago.

11. Henry, H., P. H. Black, M. Oxman, and S. M. Weissman. 1966. Stimulation of DNA synthesis in mouse line 3T3 by Simian virus 40. Proc. Nat. Acad. Sci. U.S.A. 56:1170-1176.

12. Hirsch, J. G., M. E. Fedorko, and C. M. Dwyer. 1966. Proc. 4th Int. Conf. Sarcoidosis, p. 59-69. J. Turial and J. Chabot (ed.). Masson, Paris.

13. Kit, S., R. A. de Torres, D. R. Dubbs, and M. L. Salvi. 1967. Induction of cellular deoxyribonucleic acid synthesis by simian virus 40. J. Virol. 1:738-746.

14. Mallucci, L. 1969. T-antigen and DNA synthesis in macrophages infected with polyoma virus. Nature (London) 223: 630-632.

15. Nelson, D. S. 1969. Macrophages and immunity, p. 12. John Wiley \& Sons, Inc., New York.

16. Oxman, M. N., and P. H. Black. 1966. Inhibition of SV40 T-antigen formation by interferon. Proc. Nat. Acad. Sci. U.S.A. 55:1133-1140.

17. Robbins, E., P. I. Marcus, and N. K. Gonatas. 1964. Dynamics of acridine orange-cell interaction. J. Cell Biol. 21:49-61.

18. Stecher, V. J., and G. J. Thorbecke. 1967. Sites of synthesis of serum proteins. I. Serum proteins produced by macrophages in vitro. J. Immunol. 99:643-652.

19. Takemoto, K. K., and K. Habel. 1965. Hamster ascitic fluid containing complement-fixing antibody against virus-induced tumor antigens. Proc. Soc. Exp. Biol. Med. 120: 124-127.

20. Takemoto, K. K., G. J. Todaro, and K. Habel. 1968. Recovery of SV40 virus with genetic markers of original inducing virus from SV40-transformed mouse cells. Virology 35:1-8.

21. Todaro, G. J., and H. Green. 1966. Cell growth and the initia- 
tion of transformation by SV40. Proc. Nat. Acad. Sci. U.S.A. 55:302-308.

22. Virolainen, M., and V. T. Defendi. 1967. Dependence of macrophage growth in vitro upon interaction with other cell types. In V. Defendi and M. Stoker (ed.), Growth regulating substances for animal cells in culture. Wistar Inst. Symp. Monogr. No. 7.

23. Vogt, M., R. Dulbecco, and B. Smith. 1966. Induction of cellular DNA synthesis by polyoma virus. III. Induction in productively infected cells. Proc. Nat. Acad. Sci. U.S.A. 55:956-960.

24. Volkman, A. 1966. The origin and turnover of mononuclear cells in peritoneal exudates in rats. J. Exp. Med. 124:241251.

25. Watts, J W., and H. Harris. 1959. Turnover of nucleic acids in a non-multiplying animal cell. Biochem. J. 72:142-153. 